\title{
Potassium channels in control of renal function.
}

\author{
Imenez Silva, Pedro H ; Wagner, Carsten A
}

\begin{abstract}
Potassium channels are important to control membrane potential and drive epithelial transport processes. In this issue of Kidney International, Bignon et al. report the role of the Kir4.2 $\mathrm{K}^{+}$-channel, localized at the basolateral membrane of proximal tubules, in the reabsorption of bicarbonate and the modulation of renal ammoniagenesis. The findings have implications for our understanding of how the kidney reacts to hypokalemia, an acid load, and the metabolic acidosis of patients with advanced stages of chronic kidney disease.
\end{abstract}

DOI: https://doi.org/10.1016/j.kint.2019.10.029

Posted at the Zurich Open Repository and Archive, University of Zurich ZORA URL: https://doi.org/10.5167/uzh-183744

Journal Article

Accepted Version

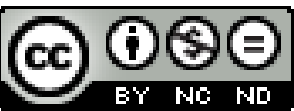

The following work is licensed under a Creative Commons: Attribution-NonCommercial-NoDerivatives 4.0 International (CC BY-NC-ND 4.0) License.

Originally published at:

Imenez Silva, Pedro H; Wagner, Carsten A (2020). Potassium channels in control of renal function. Kidney International, 97(2):253-255.

DOI: https://doi.org/10.1016/j.kint.2019.10.029 


\title{
Potassium channels in control of renal function
}

\author{
Pedro H. Imenez Silva and Carsten A. Wagner \\ Institute of Physiology, University of Zurich, Zurich, Switzerland, and National Center \\ of Competence in Research NCCR Kidney.CH, Switzerland
}

\section{Correspondence to:}

Carsten A. Wagner

Institute of Physiology

University of Zurich

Winterthurerstrasse 190

$\mathrm{CH}-8057$ Zurich

Switzerland

Wagnerca@access.uzh.ch 


\begin{abstract}
Potassium channels are important to control membrane potential and drive epithelial transport processes. In this issue of Kidney International, Bignon et al. report the role of the Kir4.2 $\mathrm{K}^{+}$-channel, localized at the basolateral membrane of proximal tubules, in the reabsorption of bicarbonate and the modulation of renal ammoniagenesis. The findings have implications for our understanding how the kidney reacts to hypokalemia, an acid load, and the metabolic acidosis of patients with advanced stages of CKD.
\end{abstract}

Key words: proximal tubule, bicarbonate reabsorption, ammoniagenesis, hypokalemia

The proximal tubule has a key role in controlling renal excretion of many metabolites (such as glucose, amino acids, or drugs), water and electrolytes by mediating the mass reabsorption (or secretion for waste products) of these mostly freely filtered substrates. The importance of these functions is evident in patients with Fanconi syndrome.

The proximal tubule is also central to the kidneys ability to adapt to systemic changes in acid-base metabolism. About 70-80\% of the filtered bicarbonate is reabsorbed by the proximal tubule through a two-step process: In the first step filtered bicarbonate combines with a proton secreted by the proximal tubule via $\mathrm{Na}^{+} / \mathrm{H}^{+}$exchangers (mostly NHE3 and NHE8 isoforms) and $\mathrm{H}^{+}$-ATPases. This step is catalyzed by GPI-anchored carbonic anhydrase IV (CAIV) located in the brush border membrane and results in the formation of carbonic $\left(\mathrm{H}_{2} \mathrm{CO}_{3}\right)$ and its dissociation into water $\left(\mathrm{H}_{2} \mathrm{O}\right)$ and carbon dioxide $\left(\mathrm{CO}_{2}\right)$. Diffusion of $\mathrm{CO}_{2}$ into the cells of the proximal tubule initiates the second step where $\mathrm{CO}_{2}$ recombines with $\mathrm{H}_{2} \mathrm{O}$ forming $\mathrm{H}_{2} \mathrm{CO}_{3}$ and dissociating into $\mathrm{HCO}_{3}^{-}$and $\mathrm{H}^{+}$. This reaction is catalyzed by cytosolic carbonic anhydrase II (CAII). The $\mathrm{H}^{+}$is recycled across the apical membrane to capture another filtered $\mathrm{HCO}_{3}{ }^{-}$whereas $\mathrm{HCO}_{3}{ }^{-}$is released back into blood by the voltage-sensitive and $\mathrm{Na}^{+}$-driven $\mathrm{Na}^{+}-\mathrm{HCO}_{3}{ }^{-}$-cotransporter $\mathrm{NBCe} 1$ (SLC4A4) located in the basolateral 
membrane. Net gain of bicarbonate is also linked to ammoniagenesis in the proximal tubule, where the synthesis of ammonia $\left(\mathrm{NH}_{3}\right)$ occurs mostly from the metabolism of glutamine. Glutamine reabsorbed from the ultrafiltrate and glutamine extracted from blood by basolateral amino acid transporters is metabolized by mitochondrial enzymes (phosphate-dependent glutamine and glutamate dehydrogenase) to produce $\alpha$ ketoglutarate and eventually malate that enters cytosolic gluconeogenesis driven by the enzyme phosphoenol pyruvate carboxykinase (PEPCK). This pathway yields the production of two $\mathrm{NH}_{3}$ and two $\mathrm{HCO}_{3}{ }^{-}$ions. When $\mathrm{NH}_{3}$ binds $\mathrm{H}^{+}$to form $\mathrm{NH}_{4}{ }^{+}$(and this process occurs with a very high rate due to the $\mathrm{pKs}$ of $\mathrm{NH}_{4}{ }^{+}$around 9.2) two additional $\mathrm{HCO}_{3}{ }^{-}$ions can be formed. These newly produced $\mathrm{HCO}_{3}{ }^{-}$ions are also transported into blood by $\mathrm{NBCe} 1$ while the $\mathrm{NH}_{4}{ }^{+}$is secreted into the tubular fluid and excreted with urine, after a complicated journey along the nephron and through the (meduallary) interstitium. Ammoniagenesis is highly regulated by various stimuli including angiotensin II, insulin, prostaglandins, acid-base status, and potassium. It is the major process by which the kidney adapts to an acid load by increasing ammoniagenesis and is suppressed during alkalemia. The reduced capacity for ammoniagenesis causes a form of renal acidosis frequently found in patients with advanced stages of chronic kidney disease.

Potassium channels are expressed in virtually all cells of the body and participate in various functions including control of membrane potential and excitability, cell differentiation, proliferation and apoptosis, and signal transduction. In epithelial cells, basolaterally located $\mathrm{K}^{+}$-channels often help to release potassium taken up by the activity of $\mathrm{Na}^{+} / \mathrm{K}^{+}-\mathrm{ATP}$ ases that import $2 \mathrm{~K}^{+}$-ions per $3 \mathrm{Na}^{+}$exported. Leaking some of these $\mathrm{K}^{+}$-ions (driven by the high intracellular $\mathrm{K}^{+}$-concentration) back to the extracellular compartment helps to bring the membrane potential across basolateral membranes closer to the potassium equilibrium potential that according to the Nernst equation is between -80 and $-90 \mathrm{mV}$. This negative membrane potential (in epithelial cells typically closer to $-60 \mathrm{mV}$ ) across the basolateral membrane is a key prerequisite for many transport processes.

Many different potassium channels are present in kidney epithelial cells lining the nephron. Most notably, the apically expressed Renal Outer Medullary $\mathrm{K}^{+}$-channel (ROMK) is required for salt reabsorption in the thick ascending limb of the loop of Henle and for $\mathrm{K}^{+}$-secretion along the connecting tubule and collecting duct. Mutations 
in this $\mathrm{K}^{+}$-channel cause Bartter syndrome. Also, other $\mathrm{K}^{+}$-channels participate in $\mathrm{K}^{+}$excretion such as the $\mathrm{Ca}^{2+}$-activated $\mathrm{BK} \mathrm{K}^{+}$-channel in the collecting duct. More recently the role of various potassium channels has been uncovered, in part through genetics of rare tubulopathies such as the EAST/SeSAME syndrome (KCNJ10/Kir4.1) ${ }^{1}$ or familial hypomagnesemia $(K C N A 1 / \mathrm{Kv1.1})^{2}$. Also, the Kir4.1/Kir5.1 heterotetramer has been implicated in sensing small changes in plasma potassium and regulation of the thiazide-sensitive $\mathrm{NaCl}$ cotransporter $\mathrm{NCC}$ in the distal convoluted tubule ${ }^{3}$. In the proximal tubule, a role for the TASK- $2 \mathrm{~K}^{+}$-channel in bicarbonate reabsorption has been demonstrated. TASK-2 is localized in the basolateral membrane of the proximal tubule ${ }^{4}$.

Here, in this issue of Kidney International, Bignon and colleagues report on the role of the inwardly rectifying $\mathrm{K}^{+}$-channel Kir4.2 (Kcnj15) in proximal tubule bicarbonate transport and ammoniagenesis ${ }^{5}$. They demonstrate that this $\mathrm{K}^{+}$-channel is localized exclusively in the basolateral membrane of the entire proximal tubule in mouse kidney. Mice with a complete genetic deletion of Kir4.2 showed a mild hyperchloremic metabolic acidosis with a more acidic urine and a reduced renal threshold for bicarbonate, the typical hallmarks of proximal renal tubular acidosis (pRTA, type II RTA). Reduced urinary ammonium excretion was also noted and did not increase to the same extent as in wildtype mice when mice were challenged with an acid load. Consequently, Kir4.2 KO mice suffered from a more severe metabolic acidosis. Since urine $\mathrm{pH}$ was also more acidic under acid loading conditions, the relationship between urinary ammonium content and urine $\mathrm{pH}$ was shifted indicating that not the inability to excrete ammonium was the cause for lower urine ammonium but reduced ammoniagenesis. Along this line, the authors found reduced induction of various key enzymes and amino acid transporters involved in ammoniagenesis in acid-loaded Kir4.2 KO mice. Kir4.2 forms Barium-sensitive $\mathrm{K}^{+}$-channels and previous experiments had established that such channels are present at the basolateral membrane of proximal tubules possibly contributing to establishing a negative membrane potential required for driving bicarbonate secretion ${ }^{6}$. The authors now demonstrate using the patch-clamp technique that the resting membrane potential of proximal tubules from Kir4.2 KO mice was considerably less negative, and that the contribution of Bariumsensitive $\mathrm{K}^{+}$-channels was reduced. These experiments indeed establish an important role of $\mathrm{K}^{+}$-channels containing the Kir4.2 subunit in clamping the membrane potential 
across the basolateral membrane to negative values around $-60 \mathrm{mV}$. The reduced membrane potential would impair NBCe1 activity and is predicted to increase intracellular $\mathrm{pH}$ due to higher intracellular bicarbonate concentrations. The authors measured intracellular $\mathrm{pH}$ in the same isolated proximal tubule preparation and show more alkaline intracellular $\mathrm{pH}$. However, whether loss of Kir4.2 directly reduces ammoniagenesis or indirectly via decreased NBCe1 activity remains open from this study. Some evidence suggests that the latter scenario may be true. Mice with complete or even heterozygous deletion of the S/c4a4 gene (encoding NBCe1) have greatly reduced expression of components of the ammoniagenic pathway ${ }^{7}$ suggesting that impaired release of bicarbonate signals back to ammoniagenesis. The reduced capacity to secrete bicarbonate into blood will possibly raise intracellular $\mathrm{pH}$ and ammoniagenic enzymes and some of the transcription factors involved in regulating glutamine uptake transporters are $\mathrm{pH}$-sensitive ${ }^{8}$.

Urinary acid excretion, and particularly ammonium excretion, is linked to renal $\mathrm{K}^{+}$-excretion. Hypokalemia stimulates proximal tubular ammoniagenesis and it has been speculated that this would be achieved through shifts of intracellular $\mathrm{K}^{+}$in exchange for extracellular $\mathrm{H}^{+}$causing intracellular acidification and stimulation of ammoniagenic enzymes. The results presented by Bignon et al. might provide a slightly alternative explanation where a fall in extracellular $\mathrm{K}^{+}$concentration would increase basolateral $\mathrm{K}^{+}$-channel activity and thereby drive the basolateral membrane potential to more negative values, higher NBCe1 activity, and a reduction in intracellular $\mathrm{HCO}_{3}-$-ions leading to intracellular acidification. Moreover, increased distal delivery of ammonium would then inhibit distal $\mathrm{K}^{+}$-secretion and enhance $\mathrm{K}^{+}$reabsorption in the collecting duct. Thus, by acting on proximal tubular $\mathrm{K}^{+}$-channels, hypokalemia would generate a (paracrine) signal, ammonium, that helps to restore normal plasma $\mathrm{K}^{+}$-levels by stimulating renal $\mathrm{K}^{+}$-conservation.

Patients with chronic kidney disease stages G4 and G5 frequently develop metabolic acidosis due to the reduced capacity of the kidney to regulate acid-base balance. Typically, urine $\mathrm{pH}$ is normal or even more acidic than in healthy individuals, but ammonium excretion is reduced due to impaired ammoniagenesis. Low urine ammonium excretion is considered as a risk factor for faster progression of kidney disease while the mechanisms underlying this association remain unclear. A role for the activation of the complement system by higher interstitial ammonium 
concentrations as well as the stimulation of the endothelin-aldosterone axis by low grade metabolic acidosis have been suggested ${ }^{9}$. Nevertheless, the cause for reduced ammoniagenesis (which would to some extent contradict the assumption of higher interstitial ammonium concentrations) is not entirely resolved. Potential explanations include inhibition of enzymes by proinflammatory factors, reduced proximal tubular mass, or downregulation of the ammoniagenic pathway in remaining nephrons. The results presented by Bignon et al. could raise the question whether dysregulation of Kir4.2 or TASK-2 $\mathrm{K}^{+}$-channels may contribute to the inhibition of proximal bicarbonate transport and ammoniagenesis in chronic kidney disease. Indeed, angiotensin II has been shown to stimulate basolateral $\mathrm{K}^{+}$-channels ${ }^{6}$ and stimulates also bicarbonate secretion. Use of RAAS inhibitors and AT1 receptor blockers may reduce this positive effect of angiotensin II in patients with CKD.

\section{Acknowledgements}

Work of the authors is supported by the Swiss National Science Foundation through the National Center of Competence in Research NCCR Kidney.CH.

\section{Disclosure}

The authors have no conflicts of interest

\section{Figure legend}

Scheme of a proximal tubule cells depicting the link between $\mathrm{HCO}_{3}{ }^{-}$reabsorption and ammoniagenesis and its possible regulation by basolateral TASK-2 and Kir4.2 channels. CAll carbonic anhydrase II, CAIV carbonic anhydrase IV, NHE3 $\mathrm{Na}^{+} / \mathrm{H}^{+}-$ exchanger isoform 3, PDG phosphate-dependent glutaminase, GDH glutamate dehydrogenase, PEPCK Phosphoenol pyuruvate carboxykinase, LAT2 system L amino acid transporter isoform 2, $A A^{0}$ neutral amino acids, SNAT3 system $\mathrm{N}$ amino acid transporter 3, Nrf2 Nuclear factor erythroid 2-related factor 2, NBCe1 electrogenic $\mathrm{Na}^{+}$-bicarbonate cotransporter isoform 1 . 


\section{References}

1. Bockenhauer D, Feather S, Stanescu HC, et al. Epilepsy, ataxia, sensorineural deafness, tubulopathy, and KCNJ10 mutations. N Engl J Med 2009; 360: 1960-1970.

2. Glaudemans B, van der Wijst J, Scola RH, et al. A missense mutation in the Kv1.1 voltage-gated potassium channel-encoding gene KCNA1 is linked to human autosomal dominant hypomagnesemia. J Clin Invest 2009; 119: 936-942.

3. Su XT, Ellison DH, Wang WH. Kir4.1/Kir5.1 in the DCT plays a role in the regulation of renal $\mathrm{K}(+)$ excretion. Am J Physiol Renal Physiol 2019; 316: F582-F586.

4. Warth $\mathrm{R}$, Barriere $\mathrm{H}$, Meneton $\mathrm{P}$, et al. Proximal renal tubular acidosis in TASK2 K+ channeldeficient mice reveals a mechanism for stabilizing bicarbonate transport. Proc Natl Acad Sci U S A 2004; 101: 8215-8220.

5. Bignon $\mathrm{Y}$, Pinelli L, Frachon $\mathrm{N}$, et al. Defective bicarbonate reabsorption in Kir4.2 $\mathrm{K}^{+}$channeldeficient mice impairs acid-base balance and ammonia excretion. Kidney Int 2019.

6. Coppola S, Fromter E. An electrophysiological study of angiotensin II regulation of $\mathrm{Na}-\mathrm{HCO} 3$ cotransport and $\mathrm{K}$ conductance in renal proximal tubules. I. Effect of picomolar concentrations. Pflugers Arch 1994; 427: 143-150.

7. Lee HW, Osis G, Harris AN, et al. NBCe1-A Regulates Proximal Tubule Ammonia Metabolism under Basal Conditions and in Response to Metabolic Acidosis. J Am Soc Nephrol 2018; 29: 1182-1197.

8. Lister A, Bourgeois S, Imenez Silva PH, et al. NRF2 regulates the glutamine transporter SIc38a3 (SNAT3) in kidney in response to metabolic acidosis. Sci Rep 2018.

9. Raphael KL. Metabolic Acidosis in CKD: Core Curriculum 2019. Am J Kidney Dis 2019; 74: 263275. 


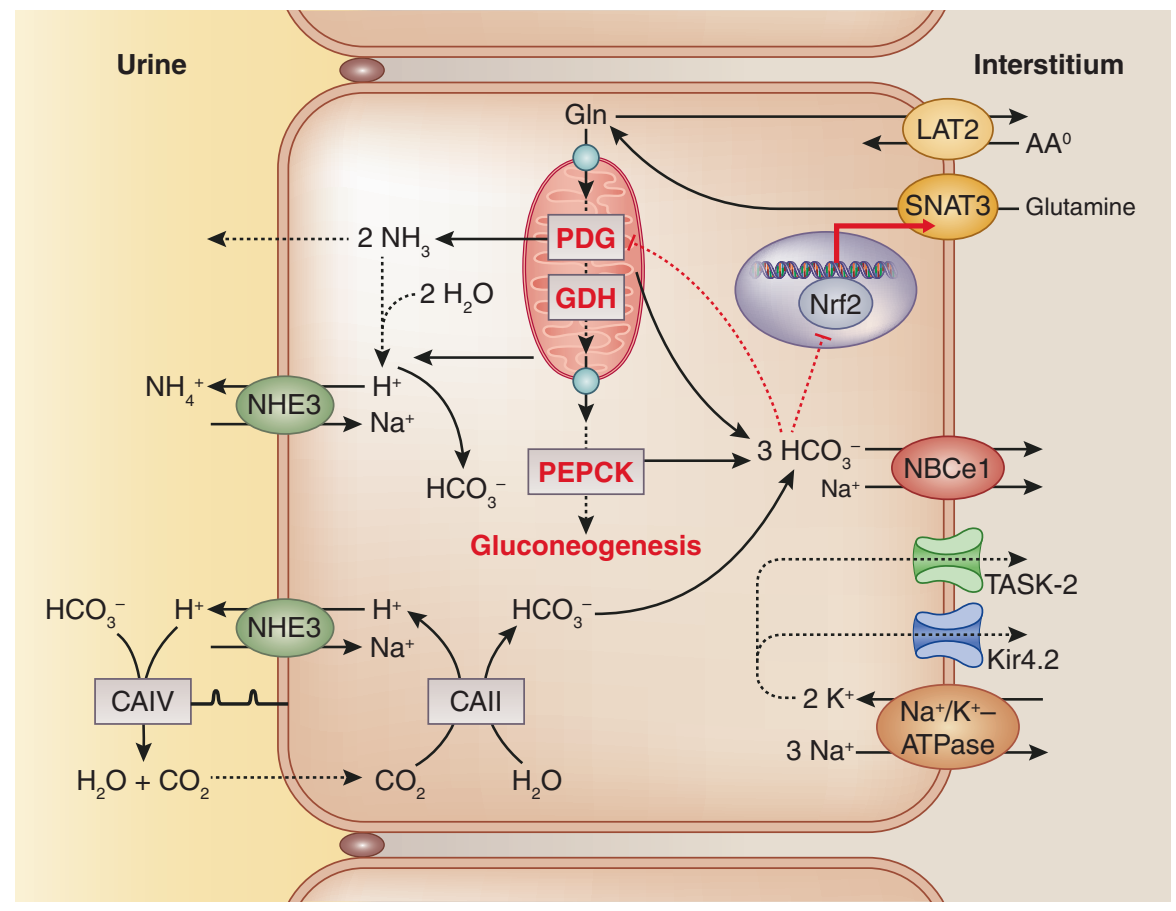

